\title{
Programa de Extensão e-TEIA: Integração do Ensino, Pesquisa e Extensão no Curso de Licenciatura em Computação na Modalidade EAD
}

\author{
${ }^{1}$ Liamara Scortegagna \\ Departamento de Ciência da Computação (DCC) - Curso de Licenciatura em \\ Computação (LiCOMP) - Universidade Federal de Juiz de Fora (UFJF) \\ 36036-900 - Juiz de Fora - MG- Brasil \\ liamara@ice.ufje.br
}

\begin{abstract}
To extende the training of students of the Degree in Computing science in the distance modality of the Federal University of Juiz de Fora (UFJF), inserting them in the daily life of public schools, with the purpose of training and informing teachers in the use of Information and Communication Technology (ICT) in the classroom, as well as improving the training of the students through an integrated teaching, research and extension proposal, is the main objective of the e-TEIA Extension Program. Motivated by this object, this work aims to present the extension program and the results achieved in its first edition.
\end{abstract}

Resumo. Ampliar a formação dos alunos do curso de Licenciatura em Computação na modalidade à distância da Universidade Federal de Juiz de Fora (UFJF), inserindo-os no cotidiano das escolas da rede pública com o intuito de capacitar e informar os professores no uso das Tecnologias de Informação e Comunicação (TIC) na sala de aula, bem como melhorar a formação dos alunos do curso através de uma proposta integrada de ensino, pesquisa e extensão, constitui o objetivo principal do Programa de Extensão e-TEIA. Motivado por este objeto, este trabalho visa apresentar o programa de extensão e os resultados alcançados na sua primeira edição.

\section{Introdução}

A modalidade de Educação a Distância (EAD) definida por inúmeros autores e pela Legislação brasileira como "modalidade educacional na qual a mediação didáticopedagógica nos processos de ensino e aprendizagem ocorre com a utilização de meios e tecnologias de informação e comunicação, com estudantes e professores desenvolvendo atividades educativas em lugares ou tempos diversos" [Brasil 2005], não é o suficiente para entender o complexo processo envolvido nesta metodologia de ensino.

Analisando as variantes que surgem na trajetória das Instituições quando da oferta da EAD, dos professores, dos tutores e alunos tais como, metodologias, ambiente

\footnotetext{
${ }^{1}$ Coordenadora do Curso de Licenciatura em Computação - LiCOMP e do Programa de Extensão eTEIA da Universidade Federal de Juiz de Fora - UFJF.
} 
virtual, materiais didáticos, comunicação, distância geográfica e temporal e outros fatores que influenciam no processo de ensino e aprendizagem não presencial. Deparamos com mais uma situação que normalmente não é usual na EAD: a oferta de programas e projetos de extensão aos alunos desta modalidade de ensino.

Pesquisas realizadas recentemente em bancos de periódicos, dissertações e bases digitais, confirmam a quase inexistência de extensão voltada para os alunos da EAD. E, isso se comprova na Universidade Federal de Juiz de Fora (UFJF) que, somente no ano de 2015, aprovou em seus editais o primeiro programa de extensão específico para alunos da EAD.

A extensão segundo Scheidemantel et al (2004) possibilita a formação do profissional cidadão e se credencia, cada vez mais, junto à sociedade como espaço privilegiado de produção do conhecimento para a superação das desigualdades sociais existentes. Como exemplo, a prática acadêmica que interliga a universidade nas suas atividades de ensino e de pesquisa com as demandas da maioria da população.

Assim, o objeto deste trabalho é apresentar o Programa de extensão universitária e-TEIA - Tecnologias de informação e comunicação na Educação: Inovação na sala de Aula, os resultados da primeira edição e a articulação entre o ensino, pesquisa e extensão no curso de Licenciatura em Computação (LiCOMP) ofertado na modalidade EAD, a partir da atuação de alunos bolsistas do curso, nas escolas da rede pública de ensino em três munícipio do Estado de Minas Gerais.

Para podermos analisar os resultados do projeto e-TEIA, apresentaremos uma revisão bibliográfica sobre Formação dos professores e as Tecnologias de Informação e Comunicação (TIC), ressaltando as potencialidades das tecnologias no processo de ensino e aprendizagem, a necessidade de que a formação do professor não pode se restringir ao simples fato de passagem de informação técnicas mas, sim de oferecer a estes, condições para entender como integrar o uso das TIC em sua prática pedagógica.

\section{O Programa de Extensão e-TEIA}

O programa de extensão e-TEIA foi planejado com o objetivo de ampliar a formação dos alunos do curso de Licenciatura em Computação, inserindo-os no cotidiano de escolas da rede pública com o intuito de capacitar e informar os professores e futuros professores no uso das Tecnologias de Informação e Comunicação na sala de aula contribuindo assim, para a melhoria do processo de ensino e aprendizagem nas escolas das cidades/polos da UFJF, bem como melhorar a formação dos alunos do curso, através de uma proposta integrada de ensino, pesquisa e extensão e ainda, aproximar os alunos da modalidade à distância com a Instituição, promovendo a construção de um processo de identidade e pertencimento.

O curso de Licenciatura em Computação é um dos sete cursos de graduação ofertados na modalidade EAD pela UFJF, através do Programa Universidade Aberta do Brasil - UAB, atuando em 13 polos de apoio presencial/cidades no Estado de Minas Gerais e possui 363 alunos matriculados.

A metodologia do programa e-TEIA é composta por seis fases: (1) a aplicação de uma pesquisa de campo inicial com o intuito de conhecer a realidade dos professores sobre o uso das TIC na sala de aula; (2) o planejamento das palestras; (3) a pesquisa bibliográfica sobre os conteúdos que serão trabalhados; (4) a efetivação da capacitação 
VI Congresso Brasileiro de Informática na Educação (CBIE 2017)

Anais dos Workshops do VI Congresso Brasileiro de Informática na Educação (WCBIE 2017)

dos professores nas escolas; (5) a aplicação de mais uma pesquisa de campo observando as percepções e possíveis mudanças de comportamento e, (6) a análise dos resultados.

A primeira edição do programa e-TEIA ocorreu no período de 2015 a 2017, contemplando três cidades do Estado de Minas Gerais, com a participação de quatro bolsistas e acompanhados por um grupo de professores do curso. A seleção dos bolsistas ocorreu por edital e, atualmente está iniciando a segunda edição do programa.

\section{Formação dos Professores e as Tecnologias de Informação e Comunicação na Educação}

O imenso potencial das TIC no processo de ensino e a aprendizagem pode trazer muitas contribuições tanto para os alunos quanto para os professores. Os recursos estimulam os alunos a desenvolverem habilidades intelectuais de pesquisa e investigação, pois o conteúdo não lhes é dado pronto. Isso os instiga a estarem mais concentrados e interessados em aprender, estimulam a buscar informações sobre um assunto e relacioná-las com aquelas adquiridas em outros momentos e, ainda, promovem cooperação entre os alunos.

Para o professor, as tecnologias auxiliam na obtenção rápida de informação sobre recursos instrucionais, interação com os alunos diferente daquela ocorrida nas aulas tradicionais. A utilização destas ferramentas permite que sejam criadas situações de aprendizagens ricas, complexas, diversificadas, não fazendo com que todo o trabalho fique sobre o professor. $\mathrm{O}$ ambiente de sala transforma-se e acontecem mudanças no perfil desse profissional, que, de acordo com Peters (2003), assume um papel de facilitador, orientador ou conselheiro.

Neste novo cenário educacional, onde as tecnologias se apresentam como auxílio para melhorar a qualidade do processo de ensino e de aprendizagem, algumas tecnologias estão se destacando. Alguns exemplos são os softwares educacionais, dispositivos móveis, aplicativos, tablets, jogos, ambientes virtuais de aprendizagem e redes sociais. Ainda podem ser citadas as tendências tecnológicas na educação, como a educação híbrida, os Massive Open Online Course (MOOC), Big Data nas escolas, BYOD ou Bring Your Own Device (traga seu próprio dispositivo), Impressoras 3D, as salas de aula invertidas, a Realidade Aumentada (RA), as interfaces naturais e as tecnologias trajáveis.

\subsection{Formação do Professor para Utilização das TIC na Sala de Aula}

Dados do uso das TIC na escolas brasileiras no ano de 2015 publicados em 2016 CETIC.BR [CETIC 2016], relatam que 93\% das escolas públicas de áreas urbanas possuíam algum acesso à Internet, enquanto a conexão a rede está universalizada nas escolas privadas. Na sala de aula, no entanto, o acesso à Internet estava disponível em $43 \%$ das públicas e em $72 \%$ das privadas. Com relação ao uso do computador e da Internet para ações pedagógicas, a pesquisa mostra que $73 \%$ dos professores o fizeram em ao menos uma das atividades com os alunos que são investigadas pela pesquisa (resultado que foi de $70 \%$ entre professores das escolas públicas e $84 \%$ das escolas privadas)

Na mesma pesquisa, quando buscamos dados sobre a formação dos professores, constata-se que $39 \%$ dos professores que responderam a pesquisa afirmara ter cursado 
uma disciplina específica na graduação sobreo uso de TIC em atividades pedagógicas, sendo que, entre os entrevistados com idade inferior a 30 anos, esse número foi de $54 \%$. Para além dos programas institucionais, 91\% dos professores disseram aprender sozinhos a utilizar o computador e Internet ou a se atualizarem sobre eles.

Apesar dos dados positivos quanto ao percentual de escolas com infraestrutura de TIC e acesso à internet e, de professores que utilizam as TIC para ações pedagógicas, ainda observamos um resultado negativo quanto a utilização das TIC na sala de aula.

O motivo se reporta de que a implantação da infraestrutura das tecnologias se baseou somente no pressuposto de que faltava apenas o computador e a internet para que o processo de modernização das escolas e do ensino se desse de forma natural, como se isso fosse um processo simples e automático e isso, pode ser observado na pesquisa CETIC.BR [CETIC 2016] que, aponta um percentual de apenas 39\% de professores que tiveram alguma formação específica durante a graduação para a utilização das TIC na sala de aula, aumentando o índice para os que possuem idade inferior a 30 anos.

Paralelamente a falta formação especifica para a atuação com TIC na sala de aula, vimos uma generalizada falta de vontade ou desconhecimento por parte dos professores que resistem ao uso das tecnologias.

O mundo, independentemente de preconceitos ou vontades de alguns professores e da má vontade da maioria dos gestores, já definiu que não poderá continuar existindo sem essas tecnologias. É simplesmente impossível conceber um mundo e uma escola sem as tecnologias, a menos que se faça a opção por uma vida eremita.

Nesse contexto, o uso das TIC na sala de aula deixa de ser uma possibilidade a mais e passa a ser uma necessidade que se impõe tão fortemente quanto a necessidade da lousa e do giz, que ainda existirão por um bom tempo. Mas, como promover esse uso?

Primeiro, são necessárias condições físicas e tecnológicas nas escolas, como, laboratórios de informática e acesso à internet. Segundo, necessitamos de professores dispostos a cumprir seu papel de educador e não apenas o seu compromisso de "dador de aulas", e, finalmente, é necessário que os professores sejam formados e capacitados para o uso das TIC.

\section{Apresentação e Análise do Dados}

A primeira edição do programa e-TEIA, ocorreu no período de novembro de 2015 à maio de 2017 e os alunos selecionados pertenciam aos polos UAB/UFJF da cidade de Juiz de Fora, Ubá e Timóteo.

Como a maioria dos alunos não residiam na cidade sede da UFJF, todas as reuniões, orientações e atividades foram desenvolvidas à distância com a mediação, interação e comunicação através do Ambiente Virtual Moodle.

\section{Fase 1: Seleção das escolas, desenvolvimento e aplicação de pesquisa de campo inicial}

$\mathrm{Na}$ primeira fase do programa os bolsistas, a partir da orientação dos professores, buscaram e definiram o objetivo da pesquisa e desenvolveram um 
VI Congresso Brasileiro de Informática na Educação (CBIE 2017)

Anais dos Workshops do VI Congresso Brasileiro de Informática na Educação (WCBIE 2017)

questionário para apurar a realidade quanto ao uso de TIC na sala de aula, bem como a definição da população a ser pesquisada.

Cada bolsista selecionou de duas a três escolas em suas cidades, e, no período de novembro de 2015 a maio de 2016, foram aplicados 121 questionários em 9 escolas da rede pública de ensino sendo seis escolas municipais e três estaduais.

O questionário foi desenvolvido a partir de cinco grupos de questões com os seguintes temas: Grupo 1: Informações sobre a formação geral e específica dos professores; Grupo 2: Utilização das TIC em sala de aula; Grupo 3: Dificuldades em usar as TIC em sala de aula e os motivos da não utilização; Grupo 4: Opinião sobre o uso das TIC no processo de ensino e aprendizagem: e ainda, no Grupo 5: Interesse do professor em participar de palestras e oficinas sobre o uso das TIC na educação.

A partir das respostas dos questionários observamos que dos 121 professores participantes, $29,8 \%$ possuem somente graduação, $60,3 \%$ possuem especialização lato sensu, $8,3 \%$ mestrado e $1,7 \%$ doutorado.

O resultado mostra que é alto o índice de professores da rede pública pesquisada que ainda possuem somente o curso de graduação e, com isso, observa-se a necessidade de formação continuada e permanente.

Quando do questionamento sobre a formação específica para o uso das TIC na educação foram solicitadas três informações: (a) Se os professores cursaram disciplinas voltadas para a utilização das TIC na educação durante sua formação (graduação); (b) Se os professores fizeram algum curso específico para a utilização das TIC na educação e, (c) Se apenas utilizaram recursos tecnológicos como alunos de algum curso de formação ou aperfeiçoamento. Assim obtivemos o seguinte resultado: 44,6\% cursaram alguma disciplina na graduação que auxiliou na utilização das TIC na educação, 32,2\% fizeram cursos específicos para a utilização das TIC e 48,7\% apenas utilizaram algum recurso tecnológico como aluno de algum curso de formação ou de aperfeiçoamento.

Apesar dos professores responderem que já tiveram algum contato com as TIC na sua formação inicial, o índice de professores que fizeram algum tipo de curso específico para o uso das TIC em sala de aula aparece como menor e isso reforça a necessidade de formação continuada, especificamente em tecnologias na educação, pois todos os processos e tecnologias evoluem de forma muito rápida.

Porém, a formação continuada e específica para utilização das tecnologias na sala de aula deve ser analisada sob dois aspectos a saber, a formação técnica e a formação pedagógica, pois somente desta forma é que podemos obter resultados concretos.

No Grupo 2 das questões solicitamos aos professores informações sobre a utilização de TIC no processo educacional, principalmente a utilização dos laboratórios de informáticas das escolas. Deste grupo, obtivemos que $62,8 \%$ nunca utilizam o laboratório de informática da escola com seus alunos, 17,4\% usam semanalmente, $6,6 \%$ uma vez por mês e 13,2\% não responderam as questões.

Na sequência (Grupo 3), questionamos se os professores tinham dificuldades em utilizar as TIC no processo educacional na escola e ainda sobre quais eram os motivos da não utilização destas. Para este grupo de questões obtivemos um índice de 59,5\% de respostas positivas, ou seja, que possuem dificuldades em utilizar os recursos 
tecnológicos disponíveis, 38,8\% não possuem dificuldade, e, 1,7\% não responderam as questões. Aprofundando os questionamentos, buscamos conhecer quais os motivos da não utilização de tais recursos, pois apenas apontar que existem dificuldades não era o suficiente para que pudéssemos dar qualquer tipo de encaminhamento pós pesquisa. Neste grupo de questões os professores poderiam pontar mais de um motivo elencado pelos pesquisadores. Assim, 50,4\% assinalaram que "Turmas grandes dificultam o acesso e o uso dos poucos recurso tecnológicos que a escola oferece"; 34,7\% alegam "serem inseguros e com falta de prática na utilização das TIC"; $29,7 \%$ apontam que é "necessário cumprir com um planejamento de conteúdo muito grande e que não sobra tempo para utilizar as TIC"; $28,1 \%$ apontam a "falta de suporte técnico nos laboratórios" como motivo para não utilização; 26,4\%, alegam que "os alunos são indisciplinados" e que isso é um impeditivo para a utilização dos recursos tecnológicos; e, ainda, 9,9\% apontou a "falta de incentivo da direção da escola" como motivo.

A maioria dos professores pesquisados apontam que possuem dificuldades para utilizar os recursos tecnológicos na sala de aula e os motivos são diversos. Sabemos que na realidade de muitas escolas, seja em relação a estrutura física/tecnológica, bem como no número de alunos em sala de aula, como apontados pelos pesquisados, podem aumentar as dificuldades na utilização das TIC no processo educacional, porém com as novas tecnologias existentes, é possível amenizar tais situações. Um exemplo é o BYOD ou Bring Your Own Device (traga seu próprio dispositivo), também conhecido como BYOT ou Bring Your Own Technology (traga sua própria tecnologia) que, referese à prática dos alunos trazerem seus próprios laptops, tablets, smartphones ou outros dispositivos móveis com eles para a escola.

Porém, os professores apontaram que se sentem inseguros com a falta de prática na utilização das TIC e esta situação só é possível superar com formação continuada e prática no dia a dia.

No Grupo 4 de questões, nosso interesse foi saber qual a opinião dos professores sobre se as "TIC facilitam ou não o processo de ensino e aprendizagem". Das respostas, $79,3 \%$ afirmam que o uso das TIC facilitam o processo de ensino e aprendizagem, $10,7 \%$ são contrários, apontando que não facilitam, $7,4 \%$ disseram que somente "as vezes facilitam" e $2,5 \%$ não responderam as questões.

Os dados apresentados relatam que os pesquisados, apesar de terem dificuldades com o uso das TIC em sala de aula, possuem consciência, na sua maioria, que as TIC facilitam o processo de ensino e aprendizagem. Essa declaração é defendida por autores como Moran [2000], Kenski [2008], Masetto [2000], Demo [2009], entre outros.

Para finalizarmos a pesquisa da primeira fase do programa e-TEIA, solicitamos aos professores se estes tinham interesse em participar de palestras sobre o uso das TIC na sala de aula ofertadas pelo grupo de bolsistas. Das respostas, obtivemos 85,9\% como positivas, $10,7 \%$ como não tem interesse e $3,3 \%$ não responderam as questões.

Com a Fase 1 do programa e-TEIA finalizado e os dados analisados, o grupo do programa e-TEIA passou a executar as Fases 2 e 3 conjuntamente.

\section{Fase 2 e 3: Definição e cronograma das palestras e pesquisa sobre os temas}

Na Fase 2, que compreendeu no período de junho a agosto de 2016, a equipe de bolsistas juntamente com os professores, iniciam a definição do cronograma das 
palestras, bem como os temas e a metodologia a serem trabalhados. Após a escolha, inicia-se a pesquisa bibliográfica, encerando-se assim também a Fase 3 do programa. Ressalta-se que, todo o trabalho ocorreu à distância utilizando webconferência e fóruns, disponibilizados no AVA do e-TEIA (Moodle).

A partir da análise do questionário inicial, foram definidos os seguintes temas para as palestras, sendo, "Redes sociais na educação", "Uso pedagógico de mídias na escola" e "Games educacionais". E, o cronograma de execução proposto para setembro a dezembro de 2016. Ressalta-se que todos os temas escolhidos, foram trabalhados com os alunos bolsistas durante as disciplinas "Informática na Educação" e "Seminário Integrador II" do curso de Licenciatura em Computação, perfazendo assim uma ligação entre o ensino e a extensão.

\section{Fase 4: Desenvolvimento/aplicação das palestras}

Nesta fase, os bolsistas retornaram às escolas escolhidas, conversaram com os diretores e agendaram horários para o desenvolvimento das palestras com os professores que responderam o questionário inicial e demostraram interesse em participar das palestras.

O número de participantes nas palestras correspondeu ao número respostas ao questionário inicial (121), apresentando uma pequena variação para mais, totalizando em 388 ouvintes nos três temas ofertados. As palestras ocorreram no período de setembro a dezembro de 2016.

\section{Fase 5: Aplicação da pesquisa de campo final}

A Fase 5, foi destinada a elaboração e aplicação de uma pesquisa aos participantes após as palestras terem sido ministradas. O questionário apresentou 8 questões, dividida em três grupos, sendo Grupo $1 \mathrm{com}$ o objetivo de avaliar as palestras, quanto ao tema, qualidade do conteúdo e o conhecimento do aluno/bolsista do e-TEIA. Grupo 2 saber se o ouvinte/professor possuía conhecimento no tema abordado, bem como se sentiu alguma dificuldade nos conteúdos que foram apresentados.

Buscou ainda através do Gripo 3 de questões, saber se o ouvinte/professor após as palestras, se sentiu mais seguro para utilizar o laboratório de informática ou outros recursos tecnológicos no processo de ensino e aprendizagem e, se utilizaria algum dos recursos tecnológico apresentados durante as palestras. Para finalizar, foi disponibilizado um espaço para que o ouvinte/professor pudesse deixar comentários, opiniões, críticas e sugestões para que o programa e-TEIA pudesse melhorar a qualidade das atividades realizadas.

Foram encaminhados os questionários no período de dezembro de 2016 a fevereiro de 2017 e, obtivemos 113 respostas. Ressalta-se que o professor/ouvinte que participou das três palestras, respondeu apenas um questionário. Sendo assim, o número de respostas obtidos foi considerável muito bom para a análise dos resultados finais.

\section{Fase 6: Análise das respostas}

A partir das respostas dos questionários, foi possível analisar as percepções dos professores/ouvintes em relação às atividades desenvolvidas pelo programa e-TEIA, a ação de um programa de extensão na sociedade a qual a instituição está inserida e as 
implicações do processo de formação do curso de Licenciatura em Computação na formação profissional do aluno/bolsista.

O primeiro grupo de questões refere-se à avaliação do aluno/bolsista, a qualidade das palestras e conteúdos. Foi solicitado que o professor/ouvinte classificasse a (s) palestra(s) em "ótima", "boa" ou "razoável". Dos respondentes, $76 \%$ consideraram "ótima", 23\% "boa" e apenas 1\% declarou que foram "razoável". Na sequência, questionamos se o palestrante (aluno/bolsista) foi claro na apresentação da palestra e, todos os respondentes afirmaram de forma positiva que sim. E ainda, em relação à qualidade do conteúdo apresentados, 95\% dos professores/ouvintes afirmaram ser "ótima" e apenas 5\% considerou "razoável". Percebe-se no resultado deste grupo de questões, a consequência da preparação do aluno/bolsista para a realização das palestras, bem como o efeito positivo da formação do curso de licenciatura na atuação destes.

No Grupo 2 de questões, objetivou-se saber sobre o conhecimento e dificuldades do professor/ouvinte com os temas abordados. Ao questionar se conhecia o(s) tema(s) abordado(s), $24 \%$ não possuía nenhum tipo de conhecimento, $29 \%$ pouco, outros $29 \%$ com conhecimento médio e apenas $18 \%$, possuía conhecimento pleno sobre o tema abordado. Em relação se estes sentiram dificuldades com os conteúdos apresentados, somente $11 \%$ afirmaram que sim e o restante se posicionou de forma negativa. Observamos aqui, a importância da atuação de um programa de extensão vinculado a um curso de licenciatura e a ação direta nas escolas.

O último grupo de questões buscamos conhecer os resultados de uma das ações do programa e-TEIA, que foram as palestras. Questionamos os professores/ouvintes se eles se sentiam mais seguros em utilizar os recursos tecnológicos apresentados durante as palestras e, das respostas, $92 \%$ afirmaram de forma positiva e apenas $8 \%$ ainda apresentaram dúvidas e insegurança. Questionamos ainda, se utilizariam algum dos recursos apresentados durante a(s) palestra(s) e quais. Destes, 65,5\% afirmaram que utilizariam sem problemas, $27,4 \%$ utilizariam às vezes (dúvidas) e apenas $7,1 \%$ não utilizariam. Dos recursos apresentados, a maioria apontou o uso de Games educacionais, apesar das redes sociais serem recursos muito conhecidos e corriqueiros entre os alunos da escola.

\section{Considerações Finais}

O envolvimento de alunos de cursos EAD na prática de programas de extensão universitária possibilita que estes tenham uma formação mais completa, pois abrange além das dimensões acadêmicas, os aspectos sociais, políticos e econômicos.

Todavia, sabemos que as ações de extensão têm ficado ausentes na EAD e, com isso, comprometeram a participação ampla dos alunos desta modalidade de ensino na interlocução da universidade com a comunidade que estão inseridos, ou seja, com suas cidades de origem.

A pesquisa realizada pelos alunos bolsistas da EAD através do programa eTEIA, focando o uso das TIC na sala de aula, é um exemplo de interlocução da UFJF com a comunidade, principalmente com os professores da rede pública de ensino, pois ao mesmo tempo que os alunos bolsistas aprendem, estão ensinando, ou seja, 
VI Congresso Brasileiro de Informática na Educação (CBIE 2017)

Anais dos Workshops do VI Congresso Brasileiro de Informática na Educação (WCBIE 2017)

repassando o conhecimento construído durante as disciplinas do curso de graduação em Licenciatura em Computação.

Com relação à pesquisa apresentada, ou seja o objetivo do programa e-TEIA, concluímos que a utilização das TIC na sala de aula pelos professores pesquisados ainda é precária. Isso foi possível observar em quase todas as respostas analisadas (pesquisa inicial - Fase 1), desde o baixo percentual de professores que fizeram algum tipo de cursos específicos para o uso das TIC, até a não utilização dos laboratórios de informática, bem como das dificuldades apresentadas por eles quando questionados sobre os motivos da não utilização das TIC no processo de ensino e aprendizagem. Porém, ao mesmo tempo que os professores afirmam não utilizarem as TIC na sala de aula, seja por quaisquer dos motivos elencados, os mesmos tem consciência de que as tecnologias facilitam e auxiliam no processo educacional.

Nas fases 2 e 3 do programa, os bolsistas organizaram e desenvolveram três palestras sendo, "Redes sociais na educação", "Uso pedagógico de mídias na escola" e "Games educacionais", observou-se aqui a ligação entre o ensino (disciplinas do curso LiCOMP) e o programa de extensão, destacando a importância do envolvimento de alunos de graduação com o desenvolvimento de ações que ampliem a formação acadêmica.

O envolvimento maior dos alunos/bolsistas com a comunidade onde a Instituição está inserida, se dá nas fases 4 e 5 do programa, onde eles ministram as palestras na escolas. Esta ação, demonstra que além dos conhecimentos técnicos construídos durante as disciplinas do curso, os conhecimentos pedagógicos também são colocados em prática. Tais conhecimentos são resultados das disciplinas de "Práticas de Ensino da Computação I e II", dentre outras da área da educação, cursadas pelos alunos. Desta forma, mais uma vez observamos a ampliação e a melhoria da formação do nosso aluno, interligando o ensino com a extensão.

Ao analisar os resultados da Pesquisa aplicada na Fase 6, retomamos ao tema da utilização das TIC na sala de aula e a capacitação continuada necessária e, que foi identificada na Fase 1 do e-TEIA. Apesar dos professores/ouvintes se sentirem mais confiantes após as palestras e, afirmarem que utilizariam os recursos apresentados, o foco ficou apenas num dos recursos, ou seja, game educacional, recurso este já conhecido pela maioria dos professores. Concluímos aqui, que é necessário uma capacitação mais aprofundada, com esclarecimentos mais embasados e com práticas na própria sala de aula, quanto da utilização de outras tecnologias no processo de ensino e aprendizagem.

Com a finalização da primeira edição do programa e-TEIA, foi possível observar e concluir a importância e a necessidade da integração de ações de pesquisa, ensino e a extensão no curso de Licenciatura em Computação, comprovando de forma positiva a ampliação na formação dos alunos bolsistas envolvidos, seja no campo tecnológico, bem como no pedagógico. Para a próxima edição do projeto, sugere-se o aprimoramento dos questionários e a oferta de oficinas práticas, além das palestras. 
VI Congresso Brasileiro de Informática na Educação (CBIE 2017)

Anais dos Workshops do VI Congresso Brasileiro de Informática na Educação (WCBIE 2017)

\section{Referências}

Brasil. (2017) Decreto $\mathrm{n}^{\circ}$ 5.622. 2005. Disponível: http://www.planalto.gov.br/ccivil_03/_ato2004-2006/2005/Decreto/D5622.htm. Acesso: junho/2017.

Cetic. (2016) Pesquisa sobre o uso das tecnologias da informação e comunicação nas escolas brasileiras [livro eletrônico] TIC educação 2015. São Paulo: Comitê Gestor da Internet no Brasil.

Demo, P. (2009) Educação hoje: "novas" tecnologias, pressões e oportunidades. São Paulo: Atlas.

e-TEIA. (2015) Tecnologias de informação e comunicação na Educação: Inovação na sala de Aula. Programa de extensão da UFJF. Juiz de Fora.

Kenski, V. M. (2008) O ensino e os recursos didáticos em uma sociedade cheia de tecnologias. In: VEIGA, I. P. A. (org). Repensando a Didática. Campinas/SP: Papirus.

Masetto, M. T. (2000) Mediação pedagógica e o uso da tecnologia. In: Moran, José Manuel (org.). Novas tecnologias e mediação pedagógica. Campinas, SP: Papirus.

Moran, J. M. et al. (2000) Novas tecnologias e mediação pedagógica. 6. ed. Campinas: Papirus.

Peters, O. (2003) A educação a distância em transição. Tradução Leila F. de Souza Mendes. Porto Alegre: UNISINOS.

Scheidemantel. S. E.; Klein. R. and Teixeira. L. I. (2004) A Importância da Extensão Universitária: o Projeto Construir. Anais do $2^{\circ}$ Congresso Brasileiro de Extensão Universitária. Belo Horizonte - 12 a 15 de setembro de 2004. Disponível: https://www.ufmg.br/congrext/Direitos/Direitos5.pdf. Acesso: junho/2017. 